\title{
Participation in environmental organizations: an empirical analysis
}

\section{BENNO TORGLER}

School of Economics and Finance, Queensland University of Technology, Brisbane, Australia; and CREMA-Center for Research in Economics, Management and the Arts, Basel, Switzerland.

Email:benno.torgler@qut.edu.au

\section{MARÍA A. GARCÍA-VALIÑAS}

Oviedo Efficiency Group, Department of Economics, School of Economics and Business, University of Oviedo, Avda. del Cristo s/n, 33006, Oviedo (Asturias), Spain; and LERNA, Laboratoire d'Economie des Ressources Naturelles, Toulouse (Midi-Pyrinees),France. Email: mariangv@uniovi.es

\author{
ALISON MACINTYRE \\ School of Economics and Finance, Queensland University of Technology, \\ Brisbane, Australia.Email: alison.macintyre@qut.edu.au
}

Submitted February 27, 2009; revised April 26, 2010, October 23, 2010; accepted February 26, 2011; first published online 24 May 2011

\begin{abstract}
The literature on volunteering has increased over the last few years. However, despite the importance of active environmental participation for solving public good and externality problems, there is still a lack of substantial empirical evidence regarding several interesting factors that influence this form of volunteering. This empirical study investigates the area by analyzing a cross-section of individuals from 38 countries using micro-data from wave III of the World Values Survey (1995-1997). The results suggest that individuals' active participation in environmental organizations is related not only to socioeconomic factors but also to political interest. We also find that a higher level of corruption is related to participation in environmental organizations. However, the situation is different for transition countries in which there was a collapse of institutional structures. The energy required to negotiate the ensuing chaos may have crowded out other forms of engagement.
\end{abstract}

\section{Introduction}

While the literature on volunteering has increased over recent years, the attention paid to specific types of voluntary participation has not kept

For advice and suggestions, thanks are due to Doris Aebi, Jouni Paavola, the participants at the 2nd Atlantic Workshop on Energy and Environmental Economics, participants at the 3rd World Congress of Environmental and Resource Economists (Kyoto), and three anonymous referees. 
pace. In particular, voluntary participation in environmental organizations is an interesting topic yet a surprisingly neglected research area. From an economics perspective, this type of volunteering holds implications for the public good of environmental quality and for dealing with externalities, at least at the local level, where active pro-environmental groups have been successful in solving certain environmental problems (Pretty and Ward, 2001). Of further interest is the fact that voluntary activities in general have the advantage of creating social output that would otherwise require paid resources (Freeman, 1997). The potential advantages of this activity are reason enough to consider possible determinants of participation in environmental organizations. Previous literature on the phenomenon of volunteering in general has suggested that socioeconomic and sociodemographic factors play a role, especially in determining who has the time, motivation or opportunity to volunteer. Furthermore, social capital and institutional quality may also influence the existing conditions or contexts within which individuals make their decisions to participate in collective action. In this paper, we extend these ideas and offer an empirical analysis of voluntary actions designed to preserve the environment.

As is common in this field of work, the concepts and variables are difficult to disentangle and to measure, and the results are often mixed, but it is hoped that the process of investigation will offer further clarity. The analysis of socio-demographic and socioeconomic factors broadly covers external factors that influence costs of participation (such as age, marital status, education and economic situation) and internal factors that can be loosely grouped into some sort of value orientation (namely, political attitudes, political interest, and participation in other voluntary organizations). The results on costs of participation are not surprising, and can explain the reduced participation of women (competing commitments), and reduced participation of those older than 30 . However, the opportunity costs of time argument is refuted by the negative relationship between being unemployed and the degree of participation. The interesting element in these regressions is the link between political interest and participation in environmental organizations. There is a positive and significant link between these variables which remains consistent after robustness checks using an instrumental variable (IV) approach.

The results of the investigation into regional differences revealed considerable disparity, suggesting that an analysis of the states' capacities could be useful in understanding citizens' involvement in environmental organizations. Previous literature on the relationship between institutional quality and corruption supported the possibility of such a process. Our findings indicate that environmental participation seems to be more important as a channel for action in developing countries in Latin America and Asia.

We also find that a higher level of corruption is positively related to participation in environmental organizations. We provide evidence of this relationship at the micro level, and at the macro level we find a strong correlation between corruption or social norms against bribing and environmental participation. This idea sits in the so-called macro-structural approach to volunteering (Salamon and Sokolowsky, 2001), which will be 
broadly described in the next section. To this end, we investigate the impact of perceived corruption on environmental organizations using a crosssection of individuals and the World Values Survey (WVS) wave III (WVS, 1995-1997) to capture the extent to which citizens are actively participating in environmental organizations. As far as we know, this is the first time the topic has been analyzed using WVS data.

Section 2 of the paper introduces the topic and describes some key factors which have emerged from the results of previous studies in proenvironmental behaviour, and in volunteering in general. Section 3 then presents the empirical results introducing the data set, the variables and the empirical approach. Finally, section 4 finishes with some concluding remarks.

\section{Factors that influence pro-environmental behavior}

As outlined in section 1, the factors influencing voluntary proenvironmental actions range from the socioeconomic and sociodemographic to the state of institutions, level of perceived corruption and level of political interest. The following section investigates the existing literature on these factors.

Our first line of inquiry into the reasons for active, passive or non-participation in environmental organizations follows the standard arguments; i.e., that volunteering is influenced by socio-demographic factors and the ability to participate in networks, either by access to networks or the costs and benefits of participation. However, Olli et al. (2001) found that socio-demographic factors explained only around 10 per cent of pro-environmental acts. Nevertheless, it is important to include these factors because they serve an important role as control variables related to the cost of participation. Some of the more usual costs are the energy and time costs, and these depend on several socioeconomic features, like age, gender, marital status, education level or income. A traditional economic approach would suggest that volunteers are more likely to be individuals with low opportunity costs of time (Menchik and Weisbrod, 1987). In fact, family issues or financial and employment commitments act as competing commitments, at odds with participation in an environmental organization. The extent of competition for the attention and time of the individual has an effect on the decision to volunteer (Martinez and McMullin, 2004; Capellari et al., 2007).

Lubell (2002) analyzed the question from a cost/benefit perspective and found that the expected value of environmental activism depends not only on the costs of participation, but also on the benefits. In this respect, two kinds of benefits for the volunteer can be identified (Lubell, 2002). Ecological activists satisfy personal and social goals at the same time. These may be linked to political and psychological characteristics and attitudes and have been labeled as 'internal or intrinsic factors' (Kollmuss and Agyeman, 2002; Cappellari and Turati, 2004). Randle and Dolnicar (2006) found that environmental volunteers have higher regional identity feelings than non-volunteers. Extraversion, altruism, solidarity and/or empathic concern for other people are other factors that matter (Cappellari and Turati, 2004; Bekkers, 2005; Randle and Dolnicar, 2006). Environmental 
values are significant too, as higher values result in a higher level of participation in environmental protection (Olli et al., 2001; Lubell, 2002; Pato and Tamayo, 2006; Randle and Dolnicar, 2006). Lubell (2002) found a positive relationship between environmental activism and environmental attitudes. Similarly, Randle and Dolnicar (2006) found that environmental volunteers present more environmentally friendly attitudes than do nonvolunteers.

We now move away from the factors that could be analyzed using the cost/benefit framework, and move towards those factors Durlauf (2002: 272) referred to when he criticized the conventional economics view of 'individual behavior in which the psychological and sociological influences on individuals are treated as having second order significance'. Some of these factors are often included under the umbrella of 'social capital', a concept that leads to 'a "socialised" account of political phenomena - in contrast to the "under-socialised" explanations offered by both rational choice theory and behaviourism' (Lowndes, 2004: 45). Durlauf (2002: 272) agrees: 'the attractiveness of social capital arguments stems, I suspect, from a growing recognition of the limitations of conventional versions of this choice-based approach'.

Even though the concept of social capital has increased in popularity over the past decade to become something of an interdisciplinary household term, the methods by which it is created and the processes and dynamics by which it is accessed are still disputed. Ambiguity regarding the direction of causality is inherent in the descriptions, definitions and measurements. Stiglitz (2000) suggests that social capital can be seen as knowledge, networks and reputation, enabling communities and individuals to address the problems of moral hazard and incentives. Putnam (1993: 167) asserts the importance of social capital for the effective governance of democracy, and expresses social capital as 'features of social organization, such as trust, norms, and networks that can improve the efficiency of society by facilitating coordinated actions'. The question remains as to whether social capital begets further interaction or whether propinquity and participation beget further social capital. The different dimensions of social capital further complicate the discussion, but most multi-dimensional descriptions are in line with Grootaert and van Bastelaer's (2002) work with the Social Capital Assessment Tool (SOCAT), categorizing social capital into three dimensions: membership in associations and networks (structural social capital), trust and adherence to norms (cognitive social capital), and collective action. In some ways, structural (network) social capital is the most visible dimension of social capital, as civic groups and the density of membership in voluntary groups are the least problematic elements to identify and measure.

The link between the network dimension of social capital and political interest was demonstrated by Bekkers (2005), who found that people more interested in politics participate more actively in voluntary associations. Torgler and Garcia-Valiñas (2007) investigate the effect of political interest on the willingness to pay increased taxes in order to protect the environment. The rationale was that informed citizens who know about environmental problems might have stronger environmental attitudes, 
because they are better aware of the possible damage. Thus, it is not only formal education that should have an impact on the willingness to accept an increase in taxes, but also the degree of political interest (referred to as informal education by Torgler and Garcia-Valiñas (2007)). It can further be assumed that politically interested people are well informed and have a high level of current knowledge about what is going on in politics and thus may also be aware of environmental issues and problems which might also lead to a higher willingness to adopt proenvironmental behaviours. Gibson and McAllister (2009: 1) argue that increased interpersonal participation in social groups contributes 'to social capital in general and especially to political involvement'. Gibson and McAllister (2009: 2) continue to argue that:

there is a considerable body of evidence that high levels of social capital are associated with higher levels of citizen engagement with the institutional framework of democratic politics. This is expressed in terms of positive orientations toward government and in higher levels of activity such as voting, volunteering and contacting.

Grootaert and van Bastelaer's (2002) conceptualization of social capital also requires the cognitive or trust dimension for the production of collective action, which can raise questions of whether the same characteristic (trust) is responsible for participation in networks. It is at this point that the direction of causality becomes most confused, and one of the key questions in the social capital literature is whether the existence of networks creates trust, or whether the existence of trust is responsible for networks. The key to answering this question may lie in the type of network and the level of trust involved with participation in the network. Networks can be formed through associations with formally constituted groups as well as non-group-based activities (Stone, 2001). For example, environmental organizations may be formal or informal. They may be large environmental organizations such as Greenpeace, with an established bureaucracy, structure and international presence. On the other hand, they may be small neighborhood cleanup groups, which are informally organized to remove weeds from the local waterway. Furthermore, networks might be formed due to participation in a choral society or a softball team, or by taking an aerobics class (Uslaner, 2002).

This distinction is relevant for our study. People who volunteer with environmental organizations are more likely to do so in order to achieve a locally important collective goal, either restoring or preserving the environment, and might undertake this volunteering with people who come from the same local area. Uslaner (2002) addresses the claims that this type of interaction will produce greater levels of trust in others, and claims that connections in such local networks will not lead to 'generalized' trust, but may lead to 'particularized' trust. The difference between these two types of trust is explored in detail in Uslaner (2002), but the importance of the topic necessitates a brief overview here. Particularized or personalized trust is a variety of trust that takes time to form, and is sometimes generated through frequent interpersonal interaction with the same individuals. On the other hand, trust sometimes arises from a general 
knowledge about the people with whom one is interacting, including knowledge of their incentives and upbringing (Durlauf and Fafchamps, 2004). This is referred to as generalized trust, and it is instantaneously extended towards other parties, as it already exists in the individual. Uslaner (2002: 135) states that 'for most all types of both formal and informal social contacts, trust is neither a cause nor an effect. People can form social bonds without drawing on moral resources'. People with generalized trust are more likely to express political interest and, in general, are more likely to participate in a whole range of activities; they are 'joiners'. According to Uslaner, this is because they learned a certain optimistic worldview from their parents.

Additionally, it is important for individuals to perceive that their personal environmental acts, and the actions of their institutions, can and will lead to a successful end. Mohai (1985) distinguished between 'internal' and 'external political efficacy' or, in Lubell's (2002) words, 'personal' and 'government efficacy'. He found that the efficacy of participation is more heavily weighted in the decision to volunteer than other variables. It is expected that higher levels of internal efficacy may lead people to participate more actively in environmental organizations (Mohai, 1985; Lubell, 2002; Martinez and McMullin, 2004).

External political or government efficacy refers to individual perceptions about the level of public institutions' responsibility and the response to citizens' environmental demands. However, the relationship is not clear. On one hand, Lubell (2002: 436) pointed out it is expected that 'citizens who believe that government actors are responsive and have an important influence on the environment are more likely to participate in environmental activism'. On the other hand, if people perceive that institutions and/or government are not able to be trusted, they may try to achieve environmental aims on their own. Weak and dysfunctional states may induce people to pursue their goals via the non-governmental sector, one example of which would be through environmental organizations.

The perceived efficacy or strength of the state is an element of institutional quality, which is a key factor in facilitating participation and better collective action outcomes in a similar way to social capital that is, by reducing transaction costs, increasing trust, and reinforcing the efficacy of the network dimension and the cognitive dimension. It is generally agreed that a functioning institutional framework will include high quality legal, economic, political and social institutions. Corruption is a serious impediment to institutional quality, leading to lack of trust and damaging reciprocity on every level. Insidious corruption involves the capture of political and economic power for the elites and for those on the inside of the circle of influence, destroying morale, reciprocity and the motivation to take collective action in providing any public good, including environmental protection. Corruption may be minimized formally through legal and political processes and informally through social sanctions.

As Paldam (2000) pointed out, corruption is the best available index of negative social capital. Pellegrini and Gerlagh (2006) found that corruption is even more significant than democracy in explaining environmental 
outcomes. Moreover, special interest groups can be another symptom of corruption or undue influence on policy makers. Formation of environmental policy is likely to be representative of many other forms of government decision making, hence Fredriksson and Svensson (2003: 1384, 1401) examine how special interest groups will influence this process. The authors claim that interaction 'between corruption and political instability is important in determination of other forms of economic policy'. The model predicts that the degree of corruption is the primary factor exerting influence over the stringency of environmental policy, and producers will find it less attractive to offer the government a bribe if there is a high degree of instability making it less likely that the government will remain in power. Hence even those who wish to bribe the government in order to receive special treatment will find other ways to have their preferences met if there is a high degree of political or institutional instability.

If people know the government is corrupt, they know the government is not going to solve their externality problems. Stiglitz (2000: 223) mentions that the government could be seen as 'precisely the mechanism that individuals have set up to reduce the welfare losses from externalities', which suggests that establishing a state with redistributive and legislative power is in itself an attempt to enable low transaction cost solutions to social dilemmas.

It seems, therefore, that corruption could result in reduced efficacy and stringency of public environmental policies, damaging the state of the environment. ${ }^{1}$ Hence, if people realize that corruption precludes the achievement of environmental protection, then it is possible that they will seek out participation in environmental organizations to pursue that aim. However, there might be limitations to such an engagement. In situations where there has been a rapid collapse of the institutional (formal and informal) and government structure (institutional and social capital vacuum) environmental participation will be lower. Due to the importance of institutional and governmental issues, we have additionally focused on the impact that corruption has on that individual decision.

\section{Empirical results}

\subsection{Methodology}

The question of primary interest in this paper relates to environmental participation and is phrased as follows:

Now I am going to read off a list of voluntary organizations; for each one, could you tell me whether you are an active member, an inactive member or not a member of that type of organization?

Environmental organization

Our dependent or response variable has the value 1 if an individual is an active member of an environmental organization, otherwise 0 .

${ }^{1}$ For example, Fredriksson et al. (2004) show that corruption has a negative impact on energy efficiency in OECD countries. Additionally, Cole (2006) found a positive direct impact of corruption on per capita emissions. 
Environmental organizations are considered to be all kinds of groups that aim to conserve natural resources and protect the environment. Thus, it is possible to find this kind of organization at the local, regional, national, even international level. However, it may be argued that there is a problem with using a cross-cultural comparison of environmental organizations, namely that the perception or reference point for what constitutes an 'environmental organization' might differ. Beck (1996) acknowledges that invoking the idea of 'nature' is going to produce disparate results depending on the social or cultural context. Harper and Brown (2003) discovered differences in perceptions of what constitutes 'the environment' between African Americans and white Americans.

We use a probit model due to the non-linear and binary nature of the dependent variable. The dependent variable in this analysis is a variable used to indicate whether individuals are an active member of a voluntary organization (value 1) or not (value 0). As a linear regression model is unbounded, the model can produce predicted probabilities that are negative or exceed unity, which are of course unrealistic. It is also not possible to arbitrarily constrain the point predictions outside the unit interval to either 0 or 1 as the error term would not satisfy the assumption of homoskedasticity. A probit model allows us to solve these problems by implementing a non-linear function that takes on values strictly between zero and one. As the estimated probit coefficients are based on a non-linear estimation technique, we cannot readily interpret the coefficients in terms of the quantitative sizes of the effects. We therefore calculate the marginal effects at the multivariate point of means to find the quantitative effect of an independent variable. The marginal effect indicates the change in the share of individuals (or the probability of) belonging actively to a voluntary environmental organization, when the independent variable increases by one unit. If the independent variable is a dummy variable, the marginal effect is evaluated with regard to the reference group.

To obtain robust standard errors, we use the Huber/White/Sandwich estimators of standard errors. We also check the robustness using standard errors adjusted for the clustering on countries, thus taking into account unobservable country-specific characteristics. Clustering leads to a decrease in the $z$-values, but has no impact on the marginal effects. The results remain robust when clustering.

A weighting variable has been applied to correct the samples and thus to obtain a reflection of the national distribution. In other words, the weighting variable corrects for obvious deviations from national population parameters in age and education. The surveys from most low-income countries undersample the illiterate portion of the public and oversample the urban areas and the more educated strata. The weighting variable corrects for these and other features of sampling. In the estimations where several countries are pooled, an additional weighting variable has been integrated. The original weight variable has been multiplied by a constant for each country to get an equal number of weighted observations (around 1,500) for each survey. The WVS provides the weighting variables (Inglehart et al., 2000). Furthermore, 'I don't $\mathrm{know}^{\prime}$ answers and missing values were omitted from all estimations. A 
Table 1. Descriptive statistics

\begin{tabular}{llll}
\hline Variables & Observations & Mean & SD \\
\hline PARTICIPATION IN ENVIRONMENTAL & 67478 & 0.035 & - \\
ORGANIZATION & & & \\
AGE 30-49 & 61015 & 0.429 & - \\
AGE 50-64 & 61015 & 0.181 & - \\
AGE 65+ & 61015 & 0.099 & - \\
FEMALE & 68735 & 0.518 & - \\
UPPER EDUCATION & 65722 & 0.199 & - \\
MIDDLE EDUCATION & 65722 & 0.544 & - \\
MARRIED & 65630 & 0.602 & - \\
FINANCIAL SATISFACTION & 65006 & 5.235 & 2.750 \\
UPPER CLASS & 64382 & 0.018 & - \\
SELF-EMPLOYED & 65388 & 0.098 & - \\
UNEMPLOYED & 65388 & 0.093 & - \\
IMPORTANCE OF POLITICS & 63520 & 2.320 & 0.947 \\
DISCUSSING POLITICS & 64627 & 1.849 & 0.654 \\
INTEREST IN POLITICS & 67349 & 2.279 & 0.955 \\
CORRUPTION & 59078 & 2.936 & 0.826 \\
NORM OF BRIBING & 67366 & 2.460 & 1.026 \\
OTHER VOLUNTARY PARTICIPATION & 60405 & 0.374 & 0.484 \\
IMPORTANCE OF FAMILY & 68569 & 3.857 & 0.405 \\
IMPORTANCE OF LEISURE & 67706 & 3.074 & 0.808 \\
IMPORTANCE OF WORK & 67937 & 3.549 & 0.700 \\
CHILDREN & 51559 & 2.370 & 1.537 \\
GENERALIZED TRUST & 67484 & 0.247 & - \\
\hline
\end{tabular}

possible criticism of this method is that these missing values could provide valuable information that should be taken into account. This certainly may be a problem if there is a large set of missing values. However, the descriptive statistics in the appendix (see table A1, available in the online appendix at http://journals.cambridge.org/EDE) show 'don't know' and missing values of our dependent variable for each country (USA has the largest number of missing values at $1 \%$ ). Hence, the variable has hardly any missing values, so it is relatively safe to omit them. Table 1 provides the descriptive statistics of all the variables, and shows that there are differences regarding the number of observations. For example, CORRUPTION and AGE have lower number of observations than other factors. However, taking into account the number of countries in the sample, missing values seem not be a serious concern. Moreover, one should note that the variable CHILDREN (lowest number of observations) has been added sequentially in the estimations.

\subsection{Data and variables}

Data used in the present study are taken from the WVS, a worldwide investigation of socio-cultural and political change, based on representative national samples. It was first carried out in 1981-1983, and subsequently 
in 1990, 1995, 1999-2001 and $2005 .^{2}$ Data from these surveys are made publicly available for use by researchers interested in how views change with time. The interesting aspect in this paper is the use of a behavioral variable instead of an attitudinal one to investigate environmental involvement or environmental preferences. Moreover, we decided to use the WVS data as it covers a broad variety of countries and variables which allow a detailed investigation of the determinants of participating actively in environmental organizations at the micro level.

Countries with fewer than 750 observations (Montenegro, the Dominican Republic, Ghana, Pakistan and Tambov) were excluded from the sample to reduce possible biases due to a lack of representativeness. Finally, Sweden could not be included as one of the control variables (EDUCATION) is coded differently. We proceed with a sample of 38 countries. ${ }^{3}$ The estimations are also performed for various geographic subsamples to compare the relevance of our independent variables in different environments. $^{4}$

We have chosen the independent variables based on the previous literature on pro-environmental behaviors and volunteerism presented in section 2. First of all, we consider several socio-demographic and economic variables. This allows us to focus firstly on 'external' factors which influence the costs of participation. In a second step we include political attitudes using three different proxies to check the robustness. Next we are going to explore whether active participation in other voluntary organizations is correlated with participation in environmental organizations. As previously discussed, a traditional economic approach would suggest that volunteers would mostly be individuals with low opportunity costs of time (Menchik and Weisbrod, 1987). We therefore control in further estimations for the number of children and the importance of work, leisure and family. Tables 1 and 2 in this paper and table A1 in the online appendix provide descriptions of the variables used. This also allows measurement of time devoted at work or at home. Time devoted to volunteering can be seen as an alternative to other activities (work in the market, work at home, and leisure).

Instead of using AGE as a continuous variable, we use four dummy variables for age cohorts. GENDER and MARITAL STATUS are additional dummy variables. From the results of previous studies no clear prediction can be formulated, but preferences for protecting the environment and time or physical restrictions should have opposite effects. Education may also be a variable of interest, and may have a positive impact. We include

${ }^{2}$ Although WVS has been used to analyze volunteerism in several countries (see, among others, Dekker and Halman (2003) or Haddad (2007)), none of the previous work has focused on active environmental participation.

${ }^{3}$ In the sample, both developing and developed countries are included, although we have fewer developing countries. However, we have considered a broader group of countries that do not have a very low income but with several wellbeing deficits and strong social inequalities (e.g., transition countries).

${ }^{4}$ A list of all the countries that were ultimately included is shown in table A1 (see online appendix). 
Table 2. Description of variables

\begin{tabular}{|c|c|}
\hline Variable & Description \\
\hline AGE & DUMMIES: AGE 30-49; AGE 50-64; 65+ (reference group, AGE < 30) \\
\hline GENDER & FEMALE (MALE in the reference group) \\
\hline \multirow[t]{4}{*}{ EDUCATION } & What is the highest educational level that you have attained (DUMMIES)? \\
\hline & LOWER EDUCATION (no formal education; incomplete primary school; completed primary school) \\
\hline & $\begin{array}{l}\text { MIDDLE EDUCATION (incomplete secondary school: technical/vocational type; complete } \\
\text { secondary school: technical/vocational type; incomplete secondary: university-preparatory type; } \\
\text { complete secondary: university-preparatory type) }\end{array}$ \\
\hline & $\begin{array}{l}\text { UPPER EDUCATION (some university-level education, without degree; university-level education, } \\
\text { with degree) }\end{array}$ \\
\hline MARITAL STATUS & $\begin{array}{l}\text { DUMMY: MARRIED = 1, all other classes (divorced, separated, widowed, single) in the reference } \\
\text { group }\end{array}$ \\
\hline $\begin{array}{l}\text { FINANCIAL } \\
\text { SATISFACTION }\end{array}$ & $\begin{array}{l}\text { How satisfied are you with the financial situation of your household? }(\text { scale } 1=\text { dissatisfied to } 10= \\
\text { satisfied) }\end{array}$ \\
\hline \multirow[t]{2}{*}{ ECONOMIC CLASS } & $\begin{array}{l}\text { People sometimes describe themselves as belonging to the working class, the middle class, or the } \\
\text { upper or lower class. Would you describe yourself as belonging to the: }\end{array}$ \\
\hline & DUMMY: UPPER CLASS, the rest (middle class, working class and lower class) is the reference group \\
\hline EMPLOYMENT STATUS & $\begin{array}{l}\text { TWO DUMMIES: SELF-EMPLOYED, UNEMPLOYED, the rest (part-time employed, at home, } \\
\text { student, retired, other) is in the reference group }\end{array}$ \\
\hline \multirow[t]{6}{*}{ CORRUPTION } & To assess the level of perceived corruption from the WVS, we use the following question: \\
\hline & How widespread do you think bribe taking and corruption is in this country? \\
\hline & Almost no public officials are engaged in it (1) \\
\hline & A few public officials are engaged in it (2) \\
\hline & Most public officials are engaged in it (3) \\
\hline & Almost all public officials are engaged in it (4) \\
\hline
\end{tabular}


NORM AGAINST BRIBING Please tell me for each of the following statements whether you think it can always be justified, never be justified, or something in between: (...) someone accepting a bribe in the course of their duties $(1=$ always justified; $10=$ never justified). We recode the variable into a 4 -point scale $(0,1,2,3)$, with the value 3 standing for 'never justified'. Responses 4 through 10 were combined into a value 0 due to a lack of variance among them

IMPORTANCE OF

POLITICS

DISCUSSING POLITICS

INTEREST IN POLITICS

OTHER VOLUNTARY PARTICIPATION

IMPORTANCE OF FAMILY

IMPORTANCE OF LEISURE

IMPORTANCE OF WORK

CHILDREN

GENERALIZED TRUST
How important is politics in your life? $(1=$ not at all important; $2=$ not very important; $3=$ rather important; 4 = very important)

When you get together with your friends, would you say you discuss political matters frequently, occasionally or never? ( $3=$ frequently; $2=$ occasionally; $1=$ never $)$

How interested would you say you are in politics? $(4=$ very interested; $3=$ somewhat interested; $2=$ not very interested; $1=$ not at all interested)

1 if active member of the following voluntary organizations: church or religious organization, sport or recreation organization, art, music or educational organization, labor union, political party, professional association, charitable organization, any other organization $(0=$ inactive member or not belonging to these organizations)

How important is family in your life? $(1=$ not at all important; $2=$ not very important; $3=$ rather important; $4=$ very important)

How important is leisure in your life? $(1=$ not at all important; $2=$ not very important; $3=$ rather important; $4=$ very important)

How important is work in your life? $(1=$ not at all important; $2=$ not very important; $3=$ rather important; 4 = very important)

Number of children

Generally speaking, would you say that most people can be trusted or that you can't be too careful in dealing with people? $(1=$ most people can be trusted $)(0=$ can't be too careful $)$

Source: Inglehart et al. (2000). 
dummy variables representative of different education levels (MIDDLE EDUCATION, UPPER EDUCATION and LOWER EDUCATION in the reference group). ${ }^{5}$

As a proxy for income we use the economic situation of an individual (dummy variable for UPPER CLASS with the remaining individuals in the reference group). Using the exact income would produce biases, because this variable is not comparable across different countries. ${ }^{6}$ It may be the case that higher income individuals have a greater demand for environmental quality, but on the other hand, the opportunity cost of their time may be very high. Furthermore, we control for FINANCIAL SATISFACTION (scale $1=$ dissatisfied to $10=$ satisfied). Participation may depend on the perceived restrictions of an individual. If a person is not satisfied with her financial situation, she has a stronger incentive to spend more time and resources in the accumulation of additional wealth rather than spending time in voluntary organizations. This allows us to get a second proxy for individuals' wellbeing. Interestingly, there is a low correlation between financial satisfaction and being rich $(\mathrm{r}=0.07)$.

Finally, another variable that approximates the economic situation of individuals is their occupational status (EMPLOYMENT STATUS). On the one hand, self-employed people may have higher opportunity costs of being in a voluntary organization. On the other hand, it may allow establishing connections that could positively influence their business. Thus, it is not possible to derive a clear prediction. There is a low positive correlation between being self-employed and being rich $(\mathrm{r}=0.01)$ and between being self-employed and financial satisfaction $(r=0.05)$.

In most of the estimations we also include regional dummy variables for the CEE and FSU (Central and Eastern Europe and Former Soviet Union countries), LATIN AMERICA, ASIA and AFRICA, leaving the industrialized economies of WESTERN EUROPE, USA, and AUSTRALIA in the reference group.

In a first step we only included 'external' factors. Thus, we have avoided including preferences and values in the model. We are aware that such an approach has its limitations and that it does not provide a complete picture of the determinants of environmental engagement. Thus, in a second step, we include political characteristics. Torgler and Garcia-Valiñas (2007), for example, have shown that political interest has a positive correlation with pro-environmental preferences. We use several proxies to check the robustness of the results (level of: IMPORTANCE OF POLITICS, DISCUSSING POLITICS and INTEREST IN POLITICS). This issue is also linked to the network dimension of social capital. In this respect, Putnam (2001: 19) cites one of the first and best descriptions of social capital written in 1916 by L.J. Hanifan:

those tangible substances [that] count for most in the daily lives of people: namely good will, fellowship, sympathy, and social intercourse among the

${ }^{5}$ See table 2 for an overview of the coding.

${ }^{6}$ In the survey, individuals are asked about the economic class they think they belong to. 
individuals and families who make up a social unit.... The individual is helpless socially, if left to himself.... If he comes into contact with his neighbor, and they with other neighbors, there will be an accumulation of social capital, which may immediately satisfy this social need and which may bear a social potentiality sufficient to the substantial improvement of living conditions in the whole community.

Thus, it can be suggested that people who think that politics is important in their lives (politically interested people) engage in intensive social interactions and, as a consequence, they are well informed and have a high level of current knowledge about what is going on in politics and thus may also be aware of environmental issues. Compared to other determinants, the aspect of political interest has been widely neglected in the environmental literature. Figure A1 (see online appendix) illustrates that societies' perceived importance of politics is highly positively correlated with active environmental participation (Pearson $r=0.362$ ). This descriptive analysis gives information about the raw effects at the macro level. We will check in a next step the robustness of these results in the multivariate analysis to get the partial effects at the micro level.

To analyze the states' capacities regarding environmental participation and implementation of public policies in general, we require a variable that reflects the link between institutional issues and participation. The perceived level of corruption is used for this purpose. Woolcock (1998: 187) points out that the 'structure of the state, the nature and extent of its involvement in civic and corporate life, and the organization of society together constitute the key factors determining whether a country succeeds or fails in development'. Hence, in the WVS, individuals are asked about the level of perceived corruption (CORRUPTION). One way to test whether the WVS question about corruption is a useful proxy is to check whether the variable is correlated with other well known indexes on corruption. Thus, we compare our variable with the corruption indexes TI (Transparency International), International Country Risk Guide (ICRG) and Quality of Government (Control of Corruption) developed by Kaufmann et al. (2003). Our index is in line with other indexes such as the Transparency International that also measure perceptions. The WVS Corruption ratings are highly correlated with the TI $(r=-0.878)$, the ICRG $(r=-0.680)$ and the Quality of Government rating $(r=-0.827)$. Additionally, in order to test the robustness of the results related to perceived corruption, we consider an additional variable (NORM AGAINST BRIBING). This variable asked individuals about the justifiability of bribing. The justifiability of bribing variable is also positively correlated with former indexes, e.g., TI CPI correlation coefficient is 0.358 and Control of Corruption (Quality of Government): 0.380 .

\subsection{Empirical evidence}

This section reports the main results (see tables 3-6 and tables A2 and A3 in the online appendix). In each table, several specifications have been shown. The main differences among specifications consist of the variables included 
Table 3. Determinants of environmental participation

\begin{tabular}{|c|c|c|c|c|c|c|c|c|c|}
\hline WEIGHTED PROBIT & Coeff. & $z$-Stat. & Marg. Effects & Coeff. & $z$-Stat. & Marg. Effects & Coeff. & $z$-Stat. & Marg. Effects \\
\hline \multirow[t]{2}{*}{ Specifications } & \multicolumn{3}{|c|}{ (1) } & \multicolumn{3}{|c|}{ (2) } & \multicolumn{3}{|c|}{ (3) } \\
\hline & \multicolumn{9}{|c|}{ Clustering on countries } \\
\hline \multirow{2}{*}{\multicolumn{10}{|c|}{ INDEPENDENT VARIABLES }} \\
\hline & & & & & & & & & \\
\hline AGE 30-49 & -0.030 & -0.92 & -0.002 & -0.030 & -0.77 & -0.002 & 0.020 & 0.60 & 0.001 \\
\hline AGE 50-64 & -0.060 & -1.48 & -0.004 & -0.060 & -0.97 & -0.004 & 0.061 & 1.44 & 0.003 \\
\hline AGE $65+$ & $-0.268^{* * *}$ & -4.57 & -0.014 & $-0.268^{* * *}$ & -2.68 & -0.014 & $-0.102^{*}$ & -1.69 & -0.005 \\
\hline FEMALE & $-0.133^{* * *}$ & -5.17 & -0.009 & $-0.133^{* * *}$ & -3.83 & -0.009 & $-0.146^{* * *}$ & -5.57 & -0.008 \\
\hline MIDDLE EDUCATION & 0.003 & 0.10 & 0.000 & 0.003 & 0.04 & 0.000 & $0.144^{* * *}$ & 4.12 & 0.008 \\
\hline UPPER EDUCATION & $0.205^{* * *}$ & 5.27 & 0.015 & $0.205^{*}$ & 1.92 & 0.015 & $0.355^{* * *}$ & 9.08 & 0.024 \\
\hline \multicolumn{10}{|l|}{ b) Marital status } \\
\hline MARRIED & -0.031 & -1.07 & -0.002 & -0.031 & -0.94 & -0.002 & -0.015 & -0.51 & -0.001 \\
\hline FINANCIAL SATISFACTION & $0.061^{* * *}$ & 11.65 & 0.004 & $0.061^{* * *}$ & 6.65 & 0.004 & $0.033^{* * *}$ & 5.83 & 0.002 \\
\hline UPPER CLASS & $0.179^{*}$ & 1.93 & 0.014 & 0.179 & 1.37 & 0.014 & $0.199^{* *}$ & 2.05 & 0.013 \\
\hline \multicolumn{10}{|l|}{ d) Employment status } \\
\hline SELF-EMPLOYED & $0.223^{* * *}$ & 5.78 & 0.017 & $0.223^{* *}$ & 2.39 & 0.017 & 0.039 & 0.99 & 0.002 \\
\hline \multicolumn{10}{|l|}{ e) Regions } \\
\hline CEE and FSU & & & & & & & $-0.455^{* * *}$ & -11.16 & -0.023 \\
\hline LATIN AMERICA & & & & & & & $0.188^{* * *}$ & 5.17 & 0.011 \\
\hline ASIA & & & & & & & $0.200^{* * *}$ & 5.42 & 0.013 \\
\hline AFRICA & & & & & & & $0.968^{* * *}$ & 13.87 & 0.125 \\
\hline
\end{tabular}




\begin{tabular}{|c|c|c|c|}
\hline WEIGHTED PROBIT & Coeff. $z$-Stat. Marg. Effects & Coeff. z-Stat. Marg. Effects & Coeff. z-Stat. Marg. Effects \\
\hline \multirow[t]{2}{*}{ Specifications } & (1) & (2) & (3) \\
\hline & \multicolumn{3}{|c|}{ Clustering on countries } \\
\hline Pseudo R2 & 0.0322 & 0.0322 & 0.0829 \\
\hline Number of observations & 48,362 & 48,362 & 48,362 \\
\hline Prob $>$ chi2 & 0.0000 & 0.0000 & 0.0000 \\
\hline
\end{tabular}

Notes: Robust standard errors and standard errors adjusted for clustering on countries. In the reference group are AGE $<30$, MALE, LOWER EDUCATION, OTHER MARITAL STATUS, OTHER CLASSES, OTHER EMPLOYMENT STATUS, WESTERN EUROPE + USA + AUSTRALIA.

Significance levels: ${ }^{*} 0.05<\mathrm{p}<0.10,{ }^{* *} 0.01<\mathrm{p}<0.05,{ }^{* * *} \mathrm{p}<0.01$.

CEE, Central Eastern European countries; FSU, Former Soviet Union countries. 
Table 4. Environmental participation and political interest

\begin{tabular}{|c|c|c|c|c|c|c|c|c|c|}
\hline WEIGHTED PROBIT & Coeff. & $z$-Stat. & Marg. Effects & Coeff. & $z$-Stat. & Marg. Effects & Coeff. & $z$-Stat. & Marg. Effects \\
\hline Specifications & & (4) & & & (5) & & & (6) & \\
\hline \multicolumn{10}{|l|}{$\begin{array}{l}\text { INDEPENDENT VARIABLES } \\
\text { a) Demographic factors }\end{array}$} \\
\hline AGE 30-49 & 0.001 & 0.02 & 0.000 & 0.002 & 0.06 & 0.000 & 0.014 & 0.41 & 0.001 \\
\hline AGE 50-64 & 0.028 & 0.65 & 0.001 & 0.034 & 0.79 & 0.002 & 0.048 & 1.12 & 0.003 \\
\hline AGE 65+ & $-0.119^{* *}$ & -1.93 & -0.006 & $-0.119^{*}$ & -1.92 & -0.006 & $-0.112^{*}$ & -1.82 & -0.005 \\
\hline FEMALE & $-0.117^{* * *}$ & -4.30 & -0.006 & $-0.116^{* * *}$ & -4.27 & -0.006 & $-0.138^{* * *}$ & -5.15 & -0.007 \\
\hline MIDDLE EDUCATION & $0.094^{* * *}$ & 2.61 & 0.005 & $0.111^{* * *}$ & 3.12 & 0.006 & $0.123^{* * *}$ & 3.45 & 0.006 \\
\hline UPPER EDUCATION & $0.267^{* * *}$ & 6.54 & 0.016 & $0.290^{* * *}$ & 7.19 & 0.018 & $0.307^{* * *}$ & 7.67 & 0.020 \\
\hline \multicolumn{10}{|l|}{ b) Marital status } \\
\hline MARRIED & -0.013 & -0.42 & -0.001 & -0.017 & -0.54 & -0.001 & -0.013 & -0.42 & -0.001 \\
\hline \multicolumn{10}{|l|}{ c) Economic variables } \\
\hline FINANCIAL SATISFACTION & $0.033^{* * *}$ & 5.70 & 0.002 & $0.034^{* * *}$ & 5.91 & 0.002 & $0.033^{* * *}$ & 5.66 & 0.002 \\
\hline UPPER CLASS & $0.195^{* *}$ & 1.95 & 0.012 & $0.207^{* *}$ & 2.07 & 0.013 & $0.198^{* *}$ & 2.00 & 0.013 \\
\hline \multicolumn{10}{|l|}{ d) Employment status } \\
\hline SELF-ĚMPLOYED & 0.017 & 0.41 & 0.001 & 0.039 & 0.99 & 0.002 & 0.023 & 0.58 & 0.001 \\
\hline UNEMPLOYED & -0.059 & -1.16 & -0.003 & -0.043 & -0.86 & -0.002 & -0.056 & -1.11 & -0.003 \\
\hline \multicolumn{10}{|l|}{ e) Regions } \\
\hline CEE and FSU & $-0.415^{* * *}$ & -10.00 & -0.021 & $-0.448^{* * *}$ & -10.92 & -0.023 & $-0.437^{* * *}$ & -10.52 & -0.022 \\
\hline LATIN AMERICA & $0.278^{* * *}$ & 7.29 & 0.017 & $0.226^{* * *}$ & 6.08 & 0.014 & $0.214^{* * *}$ & 5.81 & 0.013 \\
\hline ASIA & $0.288^{* * *}$ & 7.31 & 0.019 & $0.208^{* * *}$ & 5.52 & 0.013 & $0.183^{* * *}$ & 4.88 & 0.011 \\
\hline AFRICA & $0.988^{* * *}$ & 14.48 & 0.126 & $0.989^{* * *}$ & 14.07 & 0.128 & $0.941^{* * *}$ & 13.49 & 0.117 \\
\hline \multicolumn{10}{|l|}{ f) Political interest } \\
\hline INTEREST IN POLITICS & $0.153^{* * *}$ & 9.65 & 0.008 & & & & & & \\
\hline DISCUSSING POLITICS & & & & $0.174^{* * *}$ & 7.93 & 0.009 & & & \\
\hline IMPORTANCE OF POLITICS & & & & & & & $0.116^{* * *}$ & 8.12 & 0.006 \\
\hline
\end{tabular}


Table 4. Continued

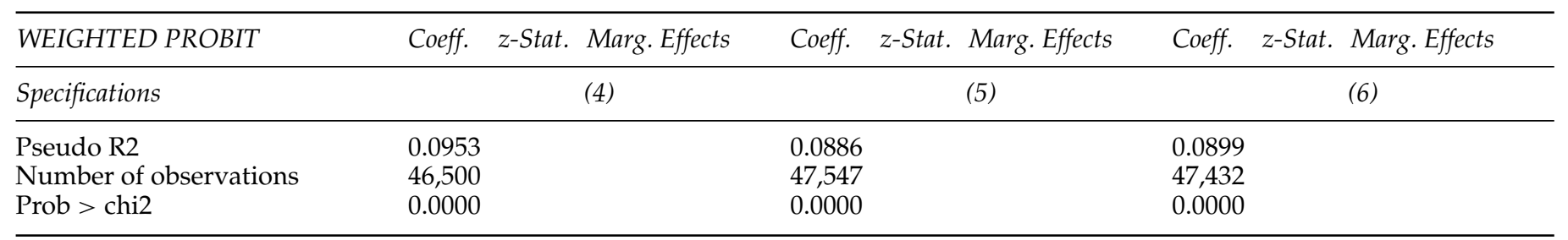

Notes: Robust standard errors. In the reference group are AGE < 30, MALE, LOWER EDUCATION, OTHER MARITAL STATUS, OTHER CLASSES, OTHER EMPLOYMENT STATUS, WESTERN EUROPE + USA + AUSTRALIA.

Significance levels: ${ }^{*} 0.05<\mathrm{p}<0.10,{ }^{* *} 0.01<\mathrm{p}<0.05,{ }^{* * *} \mathrm{p}<0.01$.

CEE, Central Eastern European countries; FSU, Former Soviet Union countries. 
Table 5. Volunteering and opportunity costs

\begin{tabular}{|c|c|c|c|c|c|c|c|c|c|}
\hline WEIGHTED PROBIT & Coeff. & $z$-Stat. & $\begin{array}{l}\text { Marg. } \\
\text { effects }\end{array}$ & Coeff. & $z$-Stat. & $\begin{array}{l}\text { Marg. } \\
\text { effects }\end{array}$ & Coeff. & $z$-Stat. & $\begin{array}{l}\text { Marg. } \\
\text { effects }\end{array}$ \\
\hline Specifications & & (10) & & & (11) & & & (12) & \\
\hline \multicolumn{10}{|l|}{ INDEPENDENT VARIABLES } \\
\hline \multicolumn{10}{|l|}{ a) Demographic factors } \\
\hline AGE 30-49 & 0.011 & 0.28 & 0.000 & 0.012 & 0.32 & 0.000 & $-0.146^{* * *}$ & -3.00 & -0.005 \\
\hline AGE 50-64 & 0.018 & 0.38 & 0.001 & 0.010 & 0.22 & 0.000 & $-0.159^{* * *}$ & -2.72 & -0.004 \\
\hline AGE 65+ & $-0.114^{*}$ & -1.64 & -0.003 & -0.112 & -1.57 & -0.003 & $-0.280^{* * *}$ & -3.20 & -0.007 \\
\hline FEMALE & $-0.105^{* * *}$ & -3.53 & -0.004 & $-0.105^{* * *}$ & -3.50 & -0.004 & $-0.147^{* * *}$ & -4.12 & -0.005 \\
\hline MIDDLE EDUCATION & 0.031 & 0.78 & 0.001 & 0.031 & 0.78 & 0.001 & 0.046 & 1.01 & 0.001 \\
\hline UPPER EDUCATION & $0.152^{* * *}$ & 3.46 & 0.006 & $0.152^{* * *}$ & 3.45 & 0.006 & $0.173^{* * *}$ & 3.40 & 0.006 \\
\hline \multicolumn{10}{|l|}{ b) Marital status } \\
\hline MARRIED & -0.009 & -0.27 & 0.000 & -0.011 & -0.31 & 0.000 & -0.054 & -1.25 & -0.002 \\
\hline \multicolumn{10}{|l|}{ c) Economic variables } \\
\hline FINANCIAL SATISFACTION & $0.024^{* * *}$ & 3.77 & 0.001 & 0.024 & 3.79 & 0.001 & $0.027^{* * *}$ & 3.68 & 0.001 \\
\hline UPPER CLASS & 0.117 & 1.13 & 0.004 & 0.123 & 1.18 & 0.005 & 0.046 & 0.42 & 0.002 \\
\hline \multicolumn{10}{|l|}{ d) Employment status } \\
\hline SELF-EMPLOYED & 0.009 & 0.19 & 0.000 & 0.007 & 0.16 & 0.000 & -0.014 & -0.27 & 0.000 \\
\hline UNEMPLOYED & -0.032 & -0.58 & -0.001 & -0.026 & -0.47 & -0.001 & -0.005 & -0.07 & 0.000 \\
\hline \multicolumn{10}{|l|}{ e) Regions } \\
\hline CEE and FSU & $-0.185^{* * *}$ & -3.88 & -0.006 & $-0.182^{* * *}$ & -3.79 & -0.006 & $-0.137^{* *}$ & -2.40 & -0.004 \\
\hline LATIN AMERICA & $0.253^{* * *}$ & 6.26 & 0.010 & $0.238^{* * *}$ & 5.77 & 0.010 & $0.260^{* * *}$ & 5.13 & 0.010 \\
\hline ASIA & $0.387^{* * *}$ & 8.82 & 0.018 & $0.386^{* * *}$ & 8.44 & 0.018 & $0.400^{* * *}$ & 7.40 & 0.018 \\
\hline AFRICA & $0.785^{* * *}$ & 10.96 & 0.061 & $0.778^{* * *}$ & 10.75 & 0.060 & $0.774^{* * *}$ & 8.11 & 0.055 \\
\hline \multicolumn{10}{|l|}{ f) Political interest } \\
\hline IMPORTANCE OF POLITICS & $0.076^{* * *}$ & 4.87 & 0.003 & $0.073^{* * *}$ & 4.55 & 0.003 & $0.080^{* * *}$ & 4.25 & 0.002 \\
\hline \multicolumn{10}{|l|}{ g) Volunteering } \\
\hline OTHER VOLUNTARY PARTICIPATION & $0.996^{* * *}$ & 26.16 & 0.052 & $0.993^{* * *}$ & 25.98 & 0.052 & $1.014^{* * *}$ & 22.41 & 0.051 \\
\hline
\end{tabular}


Table 5. Continued

\begin{tabular}{|c|c|c|c|c|c|c|c|c|}
\hline WEIGHTED PROBIT & Coeff. & $\begin{aligned} & \text { Marg. } \\
& z \text {-Stat. effects }\end{aligned}$ & Coeff. & $z$-Stat. & $\begin{array}{l}\text { Marg. } \\
\text { effects }\end{array}$ & Coeff. & $z$-Stat. & $\begin{array}{l}\text { Marg. } \\
\text { effects }\end{array}$ \\
\hline Specifications & & (10) & & $(11)$ & & & $(12$ & \\
\hline \multicolumn{9}{|c|}{ h) Opportunity costs/preferences for alternative activities } \\
\hline IMPORTANCE OF FAMILY & & & 0.009 & 0.23 & 0.000 & -0.080 & -1.55 & -0.002 \\
\hline IMPORTANCE OF LEISURE & & & 0.012 & 0.59 & 0.000 & 0.021 & 0.91 & 0.001 \\
\hline IMPORTANCE OF WORK & & & 0.026 & 1.06 & 0.001 & 0.010 & 0.34 & 0.000 \\
\hline CHILDREN & & & & & & $0.027^{* *}$ & * 2.16 & 0.001 \\
\hline Pseudo R2 & 0.1839 & & 0.1828 & & & 0.1952 & & \\
\hline Number of observations & 44,716 & & 43,844 & & & 33,442 & & \\
\hline Prob $>$ chi2 & 0.0000 & & 0.0000 & & & 0.0000 & & \\
\hline
\end{tabular}

Notes: Robust standard errors. In the reference group are AGE < 30, MALE, LOWER EDUCATION, OTHER MARITAL STATUS, OTHER CLASSES, OTHER EMPLOYMENT STATUS, WESTERN EUROPE + USA + AUSTRALIA, NOT ACTIVE IN VOLUNTARY ORGANIZATIONS.

Significance levels: ${ }^{*} 0.05<\mathrm{p}<0.10,{ }^{* *} 0.01<\mathrm{p}<0.05,{ }^{* * *} \mathrm{p}<0.01$.

CEE, Central Eastern European countries; FSU, Former Soviet Union countries. 
Table 6. Environmental participation and perceived corruption

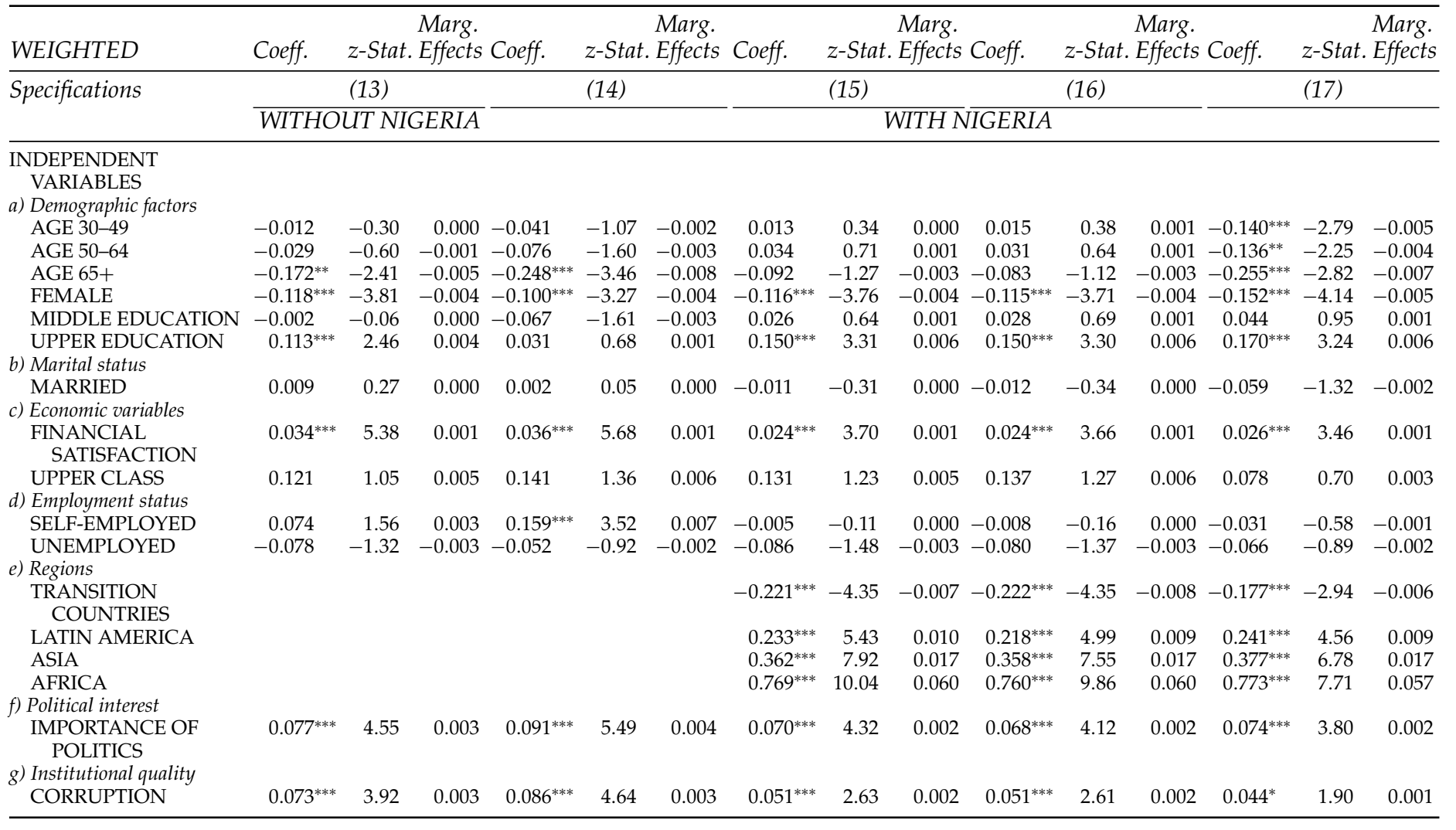


Table 6. Continued

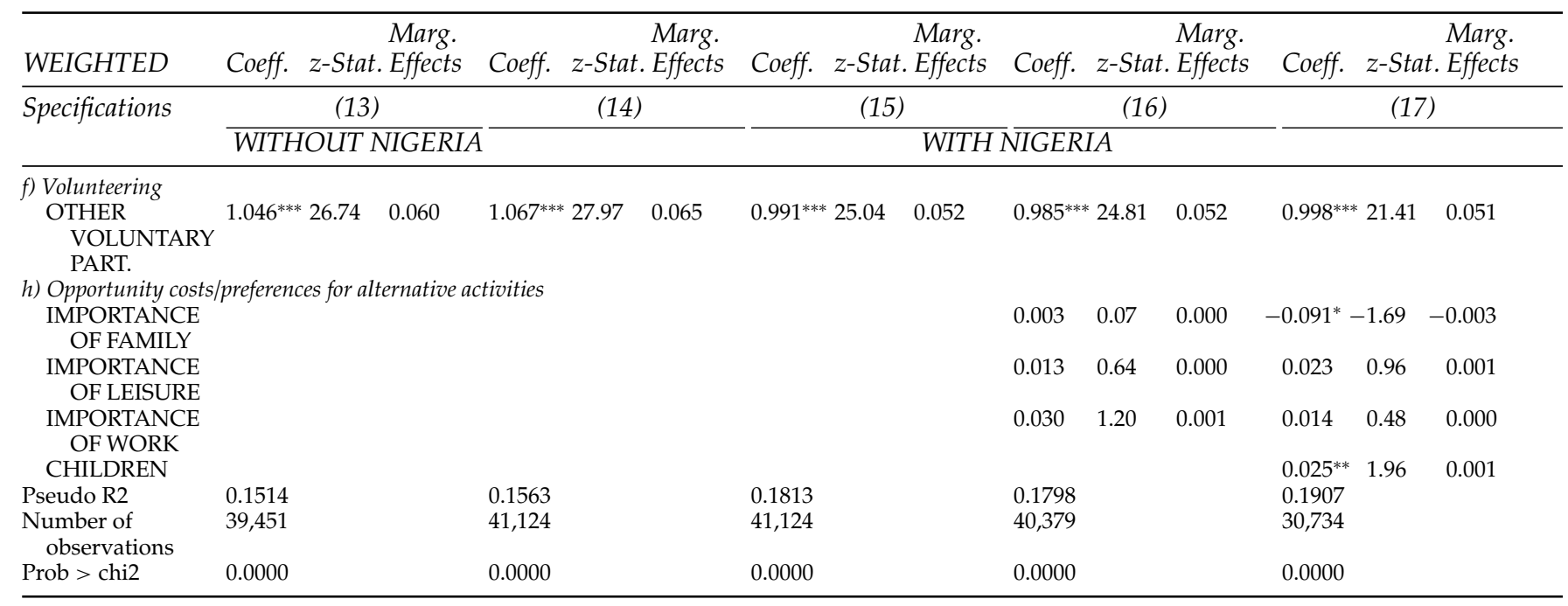

Notes: Robust standard errors. In the reference group are AGE < 30, MALE, LOWER EDUCATION, OTHER MARITAL STATUS, OTHER CLASSES, OTHER EMPLOYMENT STATUS, WESTERN EUROPE + USA + AUSTRALIA, NOT ACTIVE IN VOLUNTARY ORGANIZATIONS.

Significance levels: ${ }^{*} 0.05<\mathrm{p}<0.10,{ }^{* *} 0.01<\mathrm{p}<0.05,{ }^{* * *} \mathrm{p}<0.01$.

CEE and FSU countries not included. 
for each one. The primary objective is to investigate the robustness of our key independent variables.

At this point in the analysis, it is valid to question the appropriateness of using a single question rather than an index to proxy the level of participation. We believe that the advantage of using one single question is that problems arising due to the complexity of an index can be eliminated, especially regarding the measurement procedure or a low correlation between the items. We also observe that many studies on environmental attitudes typically measure environmental values using a single item, ${ }^{7}$ as do several studies on volunteering (Cappellari and Turati, 2004; Bekkers, 2005).

Table 3 presents the first results using the entire panel of countries. We observe that all age groups from 30 to $65+$ report a significantly lower probability of participation in environmental organizations than the reference group below 30. However, only the coefficient AGE 65+ is statistically significant in the first two estimations, showing a negative correlation. This may mean that older people face certain barriers to active participation, for example, because they might be less physically able to work in environmental organizations. Active participation would at times require considerable effort, so there is a higher probability that older people will experience physical limitations and health problems. Interestingly, women report a lower probability of participating in environmental organizations, reduced by almost 1 per cent (see all three specifications).

A positive relation between formal education and environmental participation can be observed. People with an UPPER EDUCATION are around 1.4 per cent more likely to participate in environmental organizations. Similarly, there is a positive correlation between the economic variables and participation in voluntary environmental organizations. An increase in financial satisfaction is positively associated with environmental participation. Only in the second estimation does the coefficient UPPER CLASS lose its statistical significance, but in general the marginal effects are not small. Being a member of the upper class is positively correlated with active environmental participation. There is also the tendency for selfemployed persons to show a higher level of participation in environmental organizations. However, when including a dummy for each region (in the third specification), the coefficient loses its significance, which indicates that we may expect cultural differences. On the other hand, the coefficient UNEMPLOYED has a negative sign and is not statistically significant even though it could be argued that unemployed individuals' opportunity costs of participating in voluntary organizations are lower. Our findings provide hardly any empirical foundation for the theoretical argument that participation depends on individuals' opportunity costs of time. However, we will explore this question in a better manner in table 5 .

We also find regional differences in terms of participating in environmental organizations (see specification 3). Interestingly, inhabitants of LATIN AMERICA, ASIA and AFRICA show a higher probability

${ }^{7}$ For a review see, e.g., Zelezny et al. (2000). 
of participation in voluntary environmental organizations than those of Western societies. Only the coefficients CEE and FSU show a statistically significant negative sign with relatively high marginal effects of 2.3 per cent. The results support the argument of Dekker and Van den Broek (1998: 16) who stress that in the West there is the widespread concern about the presumed decline in social and political engagement in Western society, which is claimed to affect volunteering too'.

However, the authors also stress that against such a pessimistic interpretation it can be argued that individualistic concepts of selfrealization and responsibility might also stimulate pro-social behavior. The low participation in CEE and FSU is no surprise. It can be seen as an indicator of the transition process, where the socioeconomic conditions confronting the citizens suddenly deteriorated on a massive scale and the level and quality of life declined even further. However, the regional results should be interpreted with caution as the number of countries in each region is limited.

In table 4 we extend the previous model, including three different measurements of importance of politics or political interest, including one behavioral variable (degree of political discussion). One of the key findings in this study is the fact that political interest is highly correlated with the willingness to contribute. This is consistent with the macro results obtained in figure A1 (see online appendix). This result is confirmed when using two further proxies (IMPORTANCE OF POLITICS and INTEREST IN POLITICS, and see specifications 4 and 7). Thus, we have to go beyond formal education and include individuals' interest for current political matters. This aspect has been neglected in many previous studies. It is worthwhile to mention that the impact of the variable EDUCATION is not affected by the inclusion of political characteristics.

Figures A2 and A3 (see online appendix) provide an outline of who is interested in politics. Figure A2 shows a non-linear relationship between political interest and age. Political interest increases with age, reaching the top for the age group 50-64. After that, political interest decreases. Moreover, figure A3 indicates that richer people are more interested in politics than other individuals. We also observe a positive relationship between education and political interest. However, the correlation is not that high $(r=0.2)$. Thus, it seems for these two variables that the individual characteristics driving the process of volunteering to environmental organizations are similar to those driving the process of political participation. The question remains whether this is the case for further variables and whether we may face a potential endogeneity problem.

We therefore present (in table A2 in the online appendix) three two-stage least squares (2SLS) estimations, together with the first-stage regressions also providing several diagnostic tests to deal with a potential causality problem. Comparing the first-stage regressions with dependent political interest variables with our estimations using environmental participation as dependent variable will also give us insights into whether in fact similar individual characteristics driving the process of volunteering to environmental organizations are also driving the process of political 
participation. We will use GENERALIZED TRUST as an instrument for political interest. There is hardly any correlation between generalized trust and environmental participation $(r=0.015)$. Trust in others may facilitate communication among individuals. It reduces the costs of discussing political issues. In other words, trust actively augments the ability to acquire political information at lower costs and helps to increase the individual incentive to be informed and to discuss political issues. The three first-stage regressions show that there is a strong correlation between generalized trust and political interest. Moreover, the results in table A2 also indicate that the political interest variables remain highly statistically significant in all the 2SLS. The results of the Anderson canonical correlation likelihood-ratio show that the null hypothesis can be rejected, indicating that the model is identified and the instrument seemed to be relevant in all cases. Table A2 further shows that the F-tests for the instrument exclusion set in the first-stage regression are statistically significant in all cases.

In table 5 we analyze further factors. First we add in specification (10), a variable that measures whether active volunteering in other organizations is correlated with voluntary participation in environmental organizations (see table 3). The results in specifications (10) to (12) clearly indicate that there is a strong correlation between active participation in environmental organizations and other voluntary organizations. In specification (11) we add three variables that may indicate individuals' opportunity costs of participation in environmental organizations (importance of work, family and leisure). In addition, we explore in specification (12) whether the number of children is associated with individuals' participation. We add this variable sequentially in the specification due to large number of missing values. We do not observe that the individuals' perceived importance of work, leisure and family is correlated with environmental participation. Children, on the other hand, do not seem to restrict individuals from participating in environmental organization. On the contrary, we actually observe a positive relationship, although the marginal effect is very small.

The results obtained in previous tables showed that inhabitants of the developing continents were more likely to participate in environmental organizations than those living in Western societies. This is visible for Latin America, Asia and Africa. It could be that good governance may 'crowd out' other institutions or organizations due to the complementarities between these elements of society. It may be that the presence of one institution undermines the functioning of another (Bowles, 2004), or even the need of another. On the other hand, the low participation in CEE and FSU is no surprise. It can be seen as an indicator of the transition process, where the socioeconomic conditions confronting the citizens suddenly deteriorated on a massive scale and quality of life declined even further. The rapid collapse of institutional structures produced a vacuum in these countries, followed by worsening income inequality and poverty rates (Alm et al., 2006). In such an institutional vacuum there are diminished incentives to participate in environmental organizations over other (primarily material and survival-oriented) considerations. According to Fidrmuc and Gërxhani (2005: 6), the gap, created by the sudden destruction of old institutions and the creation of new ones, provided 
a favorable environment for the persistence or even accumulation of "negative" social capital throughout transition'.

We consider the possibility that environmental participation is used as an alternative channel through which people might pursue their goals. In developing regions of Latin America or Asia, weak and dysfunctional states could precipitate such activities in the non-governmental sector. It is therefore useful to explore whether there is a positive link between corruption and environmental participation. It may be argued that perceived corruption relates more to the current politico-economic conditions, where there is still some level of institutional regime in place. It is still possible for individuals to organize themselves to solve collective action problems. Durlauf and Fafchamps (2004: 10) stress that, in poor countries, there are many situations in which the state could, theoretically, intervene to provide a public good, but where it is unable to do so because its tax base and its capacity to organize are limited. Collective action can serve as a substitute for the state. Two essential ingredients are then required: leadership and trust. A leader is required who is capable of convincing community members that they should voluntarily contribute to the public good. Trust is necessary to resolve conflicts among competing interests and to reduce fears of 'free-riding'. Our previous results indicate that trust acts as a mediator to increase political interest which then shapes environmental participation. Figure A4 (see online appendix) shows a very strong and positive correlation between corruption and environmental participation at the macro level (Pearson $r=0.552$ ). This result is also supported in figure A5 (online appendix) which documents the negative relationship between social norms against bribing and environmental participation (Pearson $r=-0.288$ ).

In a next step we explore the relationship at the micro level. Table 6 presents the results focusing on corruption, while table A3 (online appendix) reports findings focusing on the social norms against bribing. In both cases we first present the estimations without and with Nigeria, due to the fact that Nigeria might be seen as an outlier (see previous figures). The results without Nigeria are shown in specifications (13) and (18). We observe that the coefficient for the variables CORRUPTION and NORM AGAINST BRIBING is highly statistically significant at the $1 \%$ level. The effect remains robust when including Nigeria in the regression (see specification (14) and (19)). So far we have not controlled for regional effects. Adding regional dummies in specification (15) and (20) indicates that both coefficients remain statistically significant at the $1 \%$ level. These findings remain stable when adding the variables that measure the importance of work, family and leisure (specifications 16 and 21) and in specifications (17) and (22) the number of children to better control for opportunity costs. However, one should note that marginal effects are only around $0.2 \%$. Policy implications should be treated with caution. When excluding transition countries we observe a substantial increase in the marginal effects $(0.7 \%$ increase per unit). The existing literature on corruption and environmental policy supports the conclusion that institutional settings affect the way policy makers respond to environmental concerns' (Pellegrini and Gerlagh, 2006: 11). If 
individuals perceive a lack of institutional quality they seem to be willing to find alternative ways to pursue their goals. The actual process through which societies will express their preferences depends on the trust that citizens have in different institutions or channels to solve environmental problems.

\section{Concluding remarks}

Since the 1970s, the number of studies on volunteering in general, and determinants of volunteering, has been growing. However, there still exists a lack of papers investigating the determinants of voluntary participation in environmental organizations. The rapid growth of the social capital literature inspired our efforts to consider this element as an influence through the network dimension. In an environmental context, active participation in networks (a dimension of social capital) seems to improve the effectiveness of public environmental policies. This can be compared with the finding that non-active forms of participation in environmental groups do not generate the same environmental outcomes (Pretty and Smith, 2004).

This empirical study analyzes a cross-section of individuals using the WVS wave III (1995-1997) covering 38 countries. Our findings in the pooled estimations on socio-demographic factors indicate a negative correlation between age and environmental participation. Women report a lower probability of participating in environmental organizations. Interestingly, gender differences are observable in all regions except in Western societies, with the strongest marginal effects for Asia. It seems the argument that participation is based on individuals' opportunity costs is empirically not well founded. This corroborates Freeman's hypothesis (Freeman, 1997: S165), which argued that traditional economic models are not always able to explain the observed pattern of volunteering and that 'people volunteer when asked to do so for charitable causes'.

Furthermore, it is a promising line to search empirically for factors such as political interest that have largely been neglected in previous studies. Our findings show that political interest is associated with a higher environmental participation. The results also indicate that there are differences between regions. Interestingly, inhabitants of LATIN AMERICA, ASIA and AFRICA have a higher probability of participating in voluntary environmental organizations than those of Western societies, but although we work with an extensive survey, regional differences should be interpreted cautiously, as only a limited number of countries are available for each category. Our results seem to indicate that environmental participation is used as a channel for action in developing countries, where weak and dysfunctional states mean that people may instead pursue their goals through non-governmental sector activities. Such an argument is supported when investigating the relationship between corruption and individuals' active participation in environmental organizations. A positive correlation was found between the perceived level of corruption and the environmental participation. This fact suggests that individuals are able to find alternative ways to express their preferences and take action. These results are also visible when focusing on the social norms of bribing. 
Environmental participation seems to arise in situations when there are 'frictions' or, in other words, when there is a need for collective action to overcome the failures of governance. When the state is deficient, a good stock of social capital can replace the operations of formal institutions and enable collective action and cooperation to solve the problems of the group (see Rose, 1998). Such a result is consistent with Bowles and Gintis' (2002: F423) argument that 'communities may make important contributions to governance where market contracts and government fiats fail because the necessary information to design and enforce beneficial exchanges and directives cannot effectively be used by judges, government officials, and other outsiders'. However, the situation is different for transition countries during the 1990s. In extreme situations where there has been a collapse of institutional structures, this has led to a formal and informal institutional vacuum, hindering private attempts to organize environmental action and restore government effectiveness. If the institutional structures are changed completely, as they are in transition countries, there is a rapid reordering and replacement of institutions on a scale that precludes cooperation. The energy required for negotiating the ensuing chaos crowds out other forms of engagement. As explained by Kasper and Streit (1998: 3), 'modern economic life depends rather precariously on numerous written and unwritten rules. If they are widely violated - as when society collapses after a lost war or in internal chaos - many of the human interactions on which we depend for our wellbeing are no longer possible (...)'.

\section{References}

Alm, J., J. Martinez-Vazquez, and B. Torgler (2006), 'Russian attitudes toward paying taxes - before, during, and after the transition', International Journal of Social Economics 33: 832-857.

Beck, U. (1996), 'World risk society as cosmopolitan society? Ecological questions in a framework of manufactured uncertainties', Theory Culture Society 13: 1-34.

Bekkers, R. (2005), 'Participation in voluntary associations: relations with resources, personality, and political values', Political Psychology 26: 439-454.

Bowles, S. (2004), Microeconomics: Behavior, Institutions, and Evolution, New York: Princeton University Press.

Bowles, S. and H. Gintis (2002), 'Social capital and community governance', Economic Journal 112: F419-436.

Cappellari, L. and G. Turati (2004), 'Volunteer labour supply: the role of workers' motivations', Annals of Public and Cooperative Economics 75: 619-643.

Cappellari, L., P. Ghinetti, and G. Turati (2007), 'On time and money donations', CESifo Working Paper No. 2140, Munich.

Cole, M.A. (2006), 'Corruption, income and the environment: an empirical analysis', Ecological Economics 62: 637-647.

Dekker, P. and L. Halman (2003), The Values of Volunteering: Cross-Cultural Perspectives, New York: Kluwer Academic Press.

Dekker, P. and A. Van den Broek (1998), 'Civil society in comparative perspective: involvement in voluntary associations in North America and Western Europe', Voluntas: International Journal of Voluntary and Nonprofit Organizations 9: 11-38.

Durlauf, S.N. (2002), 'Bowling alone: a review essay', Journal of Economic Behavior E Organization 47(3): 259-273. 
Durlauf, S.N. and M. Fafchamps (2004), 'Social capital', NBER Working Paper No. 10485, Cambridge, MA.

Fidrmuc, J. and K. Gërxhani (2005), 'Formation of social capital in Central and Eastern Europe: understanding the gap vis-à-vis developed countries', CEPR Discussion Paper No. 5068, London.

Fredriksson, P.G. and J. Svensson (2003), 'Political instability, corruption and policy formation: the case of environmental policy', Journal of Public Economics 87: 13831405.

Fredriksson, P., H.R.J. Vollebergh, and F. Dijkgraaf (2004), 'Corruption and energy efficiency in OECD countries: theory and evidence', Journal of Environmental Economics and Management 47: 207-231.

Freeman, R.B. (1997), 'Working for nothing: the supply of volunteer labor', Journal of Labor Economics 15: S140-S166.

Gibson, R.K. and I. McAllister (2009), 'Revitalising participatory politics? The internet, social capital and political action', ASPA 2009 Toronto Meeting Paper, [Available at] http:// ssrn.com/abstract $=1451462$.

Grootaert, C. and T. van Bastelear (2002), 'Social capital: from definition to measurement', in C. Grootaert and T. van Bastelear (eds), Understanding and Measuring Social Capital: A Multidisciplinary Tool for Practitioners, Washington, DC: The World Bank.

Haddad, M.A. (2007), Politics and Volunteering in Japan: A Global Perspective, New York: Cambridge University Press.

Harper, K.M. and C.P. Brown (2003), 'Perceptions of environment among African American residents in selected neighborhoods in Hillsborough Country, Florida', Applied Environmental Education and Communication 2: 221-228.

Inglehart, R. et al. (2000), Codebook for World Values Survey, Ann Arbor: Institute for Social Research.

Kasper, W. and M.E. Streit (1998), Institutional Economics: Social Order and Public Policy, Cheltenham: Edward Elgar.

Kaufmann, D., A.M. Kraay, and A. Mastruzzi (2003), Governance Matters III: Governance Indicators for 1996-2002, World Bank, 30 June.

Kollmuss, A. and J. Agyeman (2002), 'Mind the gap: why do people act environmentally and what are the barriers to pro-environmental behaviour?', Environmental Educational Research 8: 239-260.

Lowndes, V. (2004), 'Getting on or getting by? Women, social capital and political participation', The British Journal of Politics \& International Relations 6(1): 45-64.

Lubell, M. (2002), 'Environmental activism as collective action', Environment and Behaviour 34: 431-454.

Martinez, T.A. and S.L. McMullin (2004), 'Factors affecting decisions to volunteer in nongovernmental organizations', Environment and Behaviour 36: 112-126.

Menchik, P.L. and B.A. Weisbrod (1987), 'Volunteer labour supply', Journal of Public Economics 32: 159-183.

Mohai, P. (1985), 'Public concern, and elite involvement in environmental conservation issues', Social Science Quarterly 66: 820-838.

Olli, E., G. Grendstad, and D. Wollebaek (2001), 'Correlates of environmental behaviours. Bringing back social context', Environment and Behaviour 33: 181-208.

Paldam, M. (2000), 'Social capital: one or many? Definition and measurement', Journal of Economic Surveys 14: 629-653.

Pato, C. and A. Tamayo (2006), 'Valores, creencias ambientales y comportamiento ecológico de activismo', Medio Ambiente y Comportamiento Humano 7: 51-66 [in Spanish].

Pellegrini, L. and R. Gerlagh (2006), 'Corruption, democracy, and environmental policy: an empirical contribution to the debate', Journal of Environment and Development 15(3): 332-354. 
Pretty, J. and D.J. Smith (2004), 'Social capital in biodiversity conservation and management', Conservation Biology 18: 631-638.

Pretty, J. and H. Ward (2001), 'Social capital and the environment', World Development 29: 209-227.

Putnam, R.D. (1993), Making Democracy Work. Civic Traditions in Modern Italy, Princeton, NJ: Princeton University Press.

Putnam, R.D. (2001), Bowling Alone: The Collapse and Revival of American Community, New York: Simon and Schuster.

Randle, M. and S. Dolnicar (2006), 'Environmental volunteers: are they driven by altruism and a strong feeling of regional identity?', Working Paper No. 88, Wollongong, Australia: Faculty of Commerce, University of Wollongong.

Rose, R. (1998), 'Getting things done in an anti-modern society: social capital networks in Russia', Social Capital Initiative Working Paper No. 6, Washington, DC: World Bank.

Salamon, L.M. and W. Sokolowski (2001), Volunteering in Cross-National Perspective: Evidence from 24 Countries, Working Papers of the John Hopkins Comparative Nonprofit Sector Project, No. 40, Baltimore: The John Hopkins Center for Civil Society Studies.

Stiglitz, J. (2000), Economics of the Public Sector, New York: W.W. Norton.

Stone, W. (2001), 'Measuring social capital: towards a theoretically informed measurement framework for researching social capital in family and community life', Research Paper No. 24, Melbourne: Australian Institute of Family Studies.

Torgler, B. and M.A. Garcia-Valiñas (2007), 'The determinants of individuals' attitudes towards preventing environmental damage', Ecological Economics 63: $536-552$.

Uslaner, E.M. (2002), The Moral Foundation of Trust, Cambridge: Cambridge University Press.

Woolcock, M. (1998), 'Social capital and economic development: toward a theoretical synthesis and policy framework', Theory and Society 27: 151-208.

Zelezny, L.C., P.P. Chua, and C. Aldrich (2000), 'Elaborating on gender differences in environmentalism', Journal of Social Issues 56: 443-457. 